\title{
Programando para inclusão - experiências e lições aprendidas
}

\author{
Thais Regina de Moura Braga Silva ${ }^{1}$, Gláucia Braga e Silva ${ }^{1}$ \\ ${ }^{1}$ Instituto de Ciências Exatas e Tecnológicas \\ Universidade Federal de Viçosa (UFV) \\ Florestal - MG - Brazil \\ \{thais.braga,glaucia\}@ufv.br
}

\begin{abstract}
This paper presents a report about experiences and lessons learned during the execution of a extension program that promotes actions to attract, motivate and, keep girls in the areas of Computer Science and Informatics. This program was initiated in 2015 at Federal University of Viçosa - campus Florestal involving students from a public school located in the city of Florestal Minas Gerais.
\end{abstract}

Resumo. Este artigo apresenta um relato de experiências e lições aprendidas durante a execução de um programa de extensão que promove ações para atrair, acolher e manter meninas nos cursos de Computação e Informática. Esse programa foi iniciado em 2015 na Universidade Federal de Viçosa - campus Florestal em parceria com uma escola pública da cidade de Florestal-Minas Gerais.

\section{Introdução}

Historicamente as mulheres não são incentivadas a participar do mercado de trabalho na área de Tecnologia da Informação (TI) [Abbate 2012]. Dados estatísticos coletados em todo o mundo e, particularmente no Brasil, mostram que o percentual de mulheres na área de TI é extremamente baixo. Em nosso país, somente $1 / 4$ da força de trabalho nessa área é ocupada por mulheres. Dentre essas, a minoria ocupa cargos de chefia. Ainda mais alarmante é o fato de que o rendimento médio das mulheres que atuam na área é, em geral, cerca de $34 \%$ menor do que o dos homens que ocupam os mesmos cargos, de acordo com dados do Censo de 2010. Quando são comparados os salários de homens e mulheres ocupando cargos de chefia, a diferença salarial se torna mais evidente, chegando a $65 \%$ [Moro et al. 2010].

O problema da ausência feminina nos postos de trabalho da área de TI passa, necessariamente, pela ausência de meninas e jovens em cursos de formação técnica e especializada nesta área. Pesquisas recentes mostram que o desinteresse de meninas em idade escolar, mesmo aquelas que se identificam com disciplinas como matemática e física, se dá pelo desconhecimento sobre os cursos correlatos e das atividades desempenhadas pelo profissional desse mercado de trabalho, bem como pela disseminação na sociedade de estereótipos equivocados sobre as pessoas (e sobretudo as mulheres) que trabalham com TI [Matsuura 2016]. O debate sobre este assunto tem atraído a atenção da sociedade recentemente e algumas iniciativas para enfrentá-lo têm sido conduzidas em escolas, universidades e na iniciativa privada [Google 2018, Nakamura et al. 2017, Pessoa et al. 2017].

Em busca de iniciativas que abram as portas dos cursos da área de TI para meninas, e, em especial, visando contribuir para que aquelas que obtiveram uma formação 
técnica inicial possam se sentir interessadas e capazes de prosseguir estudando, passando da informática à computação, as autoras deste trabalho criaram um programa de extensão universitária, denominado MinasCoders, composto pelos projetos PinkBits e ++meninasComp, conduzidos, desde 2015, na Universidade Federal de Viçosa, campus Florestal (UFV-Florestal). Tais projetos estão correlacionados e suas equipes trabalham para um único objetivo final: atrair, acolher e manter meninas nos cursos da área de TI oferecidos pelo campus. Em particular, o projeto ++meninasComp está atrelado às atividades de caracterização do público-alvo e apresentação e treinamento em atividades ligadas ao desenvolvimento de lógica computacional e programação. Já o projeto PinkBits mantém grupos de estudo de programação e fomenta a formação e participação de competidores e equipes para as principais competições nas áreas de informática e computação do país.

O objetivo deste trabalho é, portanto, apresentar vivências experimentadas no âmbito dos projetos PinkBits e ++meninasComp ao longo de um triênio de existência dos mesmos (2015-2017), mostrando que é possível extrair delas um conjunto de lições que podem ser discutidas e aplicadas em outros projetos com propostas similares.

As iniciativas que visam acolher meninas e mulheres na área de TI, especialmente no Brasil, são ainda muito recentes. Desta forma, é de grande relevância o compartilhamento de experiências para o debate com a comunidade envolvida como forma de aprimorar os projetos em curso, dando a eles perspectivas mais acertivas e aumentando sua efetividade; construir redes de colaboração que ampliam e fortalecem as iniciativas; e ainda estimular a criação de novas frentes, equipes, projetos e propostas, de maneira que elas possam se espalhar e atingir um maior número de pessoas.

O restante deste trabalho está organizado da seguinte forma: a seção 2 contém dados sobre os projetos PinkBits e ++meninasComp no triênio 2015-2017. A seção 3 apresenta um conjunto de lições aprendidas ao longo do triênio. Por fim, algumas conclusões e perspectivas de direcionamento futuro estão descritas na seção 4.

\section{Um triênio de experiências}

Desde 2015, as ações extensionistas do programa MinasCoders vêm sendo coordenadas por duas docentes do curso de graduação em Ciência da Computação da UFV-Florestal. A equipe do projeto abrange ainda alunas, bolsistas e voluntárias, matriculadas no mesmo curso ou no curso Técnico em Informática do Centro de Desenvolvimento Agrário de Florestal (CEDAF/UFV), escola técnica vinculada à UFV-Florestal; servidores técnicoadministrativos da IES; e membros das escolas públicas do município de Florestal/MG. As bolsas concedidas são oriundas de programas institucionais de apoio a projetos de extensão.

Com relação ao público-alvo, em 2015, houve participação de alunos do ensino médio da escola estadual Serafim Ribeiro de Rezende, localizada em Florestal/MG, matriculados nos cursos técnicos da CEDAF/UFV. Em 2016, as ações envolveram apenas os alunos do 10 ano do curso Técnico em Informática. Por fim, em 2017, participaram do programa MinasCoders alunos do 1o, 2o e 3o anos do curso Técnico em Informática e alunos do curso superior em Ciência da Computação da UFV-Florestal. 


\subsection{Ano 1 (2015): Conhecendo a realidade local}

Em 2015, os projetos PinkBits e ++meninasComp trabalharam a conscientização do tema "Mulheres na Computação" na UFV-Florestal e na comunidade local. Foi criada uma comunidade virtual no Facebook (https://www.facebook.com/pinkbitsflorestal/), com o intuito de divulgar os projetos, compartilhar notícias e curiosidades relacionadas ao tema e criar um canal de comunicação com o público-alvo. O primeiro contato efetivo com o público-alvo se deu por meio da aplicação de um questionário virtual para levantamento do perfil dos estudantes, com a participação de 90 alunos do ensino médio da escola estadual Serafim Ribeiro de Rezende, matriculados no ensino técnico da CEDAF/UFV, sendo 33 meninas e 57 meninos. O questionário continha 32 perguntas que endereçavam o interesse por tecnologia, escolaridade dos familiares, matérias preferidas, entre outras. A partir desse primeiro contato e das respostas dos questionários, já foi possível observar o baixo interesse das meninas $(24 \%)$ em seguir cursos superiores na área de exatas.Não foram oferecidos ou distribuídos incentivos para as meninas que respondessem ao questionário e, embora relativamente longo, não houveram relatos formais ou informais de problemas devido ao tamanho do mesmo. Neste primeiro ano, merece destaque a participação de duas integrantes da equipe na primeira edição da conferência Latinity ${ }^{1}$ - Latin American Women in Technology. Na ocasião, houve apresentação de uma palestra sobre as atividades extensionistas desenvolvidas no âmbito dos projetos PinkBits e ++meninasComp. Ressalta-se que o evento não possuía anais nessa edição.

\subsection{Ano 2 (2016): Atraindo meninas para programação lúdica}

No ano de 2016, em virtude das experiências vivenciadas em 2015, houve uma redefinição do público-alvo do projeto que passou a abranger apenas os alunos do ensino médio que estivessem matriculados no curso Técnico em Informática (TI) da CEDAF/UFV. Dessa forma, o questionário de levantamento de perfil foi novamente aplicado, após algumas adequações, contando com a participação de 31 alunos do 10 ano do TI.

Nesta edição, houve a participação da equipe dos projetos PinkBits e ++ meninasComp na semana acadêmica do curso de Ciência da Computação, em uma mesa redonda que abordou o tema He For She, proposto pela ONU Mulheres, com o intuito de envolver os meninos nas discussões. A equipe promoveu ainda dinâmicas com atividades lúdicas realizadas com a turma do 1o ano do curso Técnico em Informática, com o intuito de incentivar o interesse dos alunos pela área, em especial, pela programação de computadores. Essas dinâmicas abordaram a programação em blocos, utilizando o Google CWC (Coding With Chrome $^{2}$ ), junto à disciplina de Lógica de Programação. Neste ano, merece destaque a premiação de Mérito em Extensão, na categoria Ensino Médio, a partir da participação da equipe em um evento de Ensino, Pesquisa e Extensão da UFV-Florestal.

\subsection{Ano 3 (2017): Inserindo a competição}

Em 2017, o questionário de levantamento de perfil foi atualizado com novas perguntas para ser aplicado junto aos alunos do 1o, 2o e 3o anos do curso Técnico em Informática da CEDAF/UFV. Ressalta-se que os alunos do 2 o e do 30 anos já haviam respondido questionários nos anos de 2015 e 2016 . Ao todo, houve participação de 47 alunos (18 meninas), sendo 17 do $1^{\circ}$ ano e 30 dos $2^{\circ}$ e $3^{\circ}$ anos.

\footnotetext{
${ }^{1}$ Em 2018, a conferência se encontra em sua 4a edição - http://latinity.co/en/

${ }^{2}$ https://codingwithchrome.foo/
} 
Nesta edição, os projetos abordaram o tema programação mais a fundo e investiram na realização de treinamentos semanais para preparar um grupo de alunos e alunas para competições nas áreas de Informática e Computação. Para isso, foram formados dois grupos de treinamentos, coordenados por uma aluna do curso de Ciência da Computação: um grupo de alunas e alunos do curso Técnico em Informática; e um grupo de alunas e alunos do curso de Ciência da Computação. Para apoiar e facilitar as interações entre a equipe e o público-alvo, foram utilizados a comunidade virtual no Facebook, grupos de Whatsapp e fóruns de discussão. Além disso, igualmente importantes foram os momentos de socialização realizados ao final de cada semestre, como forma de celebrar a perserverança e a dedicação do grupo e as conquistas obtidas com as participações nas competições. Dentre os resultados positivos dessa última edição, destacam-se a classificação de alguns envolvidos em duas competições de destaque, a saber a Olimpíada Brasileira de Informática - OBI (etapa nacional) e a Collegiate Cup Brazil.

Por fim, foram reformuladas as comunidades virtuais no Facebook, com criação de uma específica para o programa MinasCoders (https://www.facebook.com/minascodersflorestal/).

\section{Lições aprendidas}

Reunimos parte da memória e do aprendizado na condução dos projetos PinkBits e ++meninasComp, e apresentamo-os abaixo na forma de lições aprendidas. O intuito é o de deixar disponível na literatura registros que possam auxiliar demais coordenadores e membros de projetos semelhantes na elaboração e condução dos mesmos.

1. Não separar completamente os gêneros: logo no primeiro ano de nosso triênio, ficou claro o sentimento de segregação causado por escolher convocar apenas meninas para participarem dos projetos. Nos anos seguintes, ao serem incluídos meninos nos grupos, sempre em número no máximo igual ao de meninas, foi notável a maior aceitação geral dos projetos e a melhor integração entre os participantes.

2. Não forçar atividades e/ou público: muitas vezes, no desejo de cumprir com tudo o que foi planejado pelos projetos, e até mesmo de ver concretizados os objetivos traçados, acaba-se criando estratégias não de convite mas de obrigatoriedade de participação. Isso leva a uma participacão desmotivada, além da disseminação de informações negativas sobre os projetos e da área como um todo.

3. Utilizar estratégias que envolvam um objetivo final claro: ao iniciar os projetos, durante o primeiro ano, previmos a realização de atividades tais como palestras, minicursos e oficinas. Entretanto, como os eventos não tinham relação direta entre si e um objetivo final claro para o público-alvo, observamos que as meninas acabavam se desmotivando ao longo do período de realização dos projetos.

4. Manter contato permanente entre os níveis médio/técnico e superior: um grande benefício da execução dos projetos PinkBits e ++meninasComp na universidade onde foram criados é o fato de existirem tanto cursos técnico em Informática como superior em Ciência da Computação. Explorando esse contato tão direto, foi possível criar dinâmicas que aproximavam esses dois grupos, o que fortaleceu a participação do público-alvo.

5. Deixar espaço para que próprio grupo crie atividades: principalmente durante o segundo e terceiro anos do programa, foi possível notar que, uma vez engajado aos 
projetos, o público-alvo frequentemente deseja participar na composição de atividades. As propostas criadas, em geral, são muito alinhadas com as demandas e as características desse público, conseguindo adesão e resultados muito positivos.

6. Não repetir atividades com o mesmo formato e tema consecutivamente: uma vez que o público-alvo é normalmente composto por jovens, a repetição de atividades e formatos, a cada edição, acaba se tornando um ponto de exaustão, desmotivando pela falta de novidades e pelo estabelecimento de uma rotina.

7. Criar e manter "espaços sociais" (criar vínculos): o terceiro e último ano de execução do programa de extensão do triênio foi, notoriamente o mais significativo, em termos de engajamento. Foi observado que, este foi também o ano em que foram utilizados mais amplamente espaços e estratégias de solicialização, como o uso de redes sociais e a organização de confraternizações.

\section{Considerações Finais}

Neste trabalho, não há nenhuma pretensão de se generalizar ou mesmo esgotar a lista de lições aprendidas. Deve ficar claro que as questões colocadas foram fruto das vivências de dois projetos particulares em um contexto específico. Entretanto, acreditando que projetos similares compartilharão características com aqueles aqui apresentados, ainda que parcialmente, as lições devem ser úteis e de interesse. Como trabalhos futuros, uma vez que ambos os projetos continuam em andamento, espera-se continuar realizando observações das atividades em condução e seus resultados, bem como a inserção de novas ações, gerando assim novas lições aprendidas.

\section{Referências}

Abbate, J. (2012). Recoding Gender: Women's Changing Participation in Computing. The MIT Press.

Google (2018). Made with code. [Disponível em https://www.madewithcode.com/ Acesso em 26 MAR.2018].

Matsuura, S. (2016). Mulheres ainda são poucas no mercado de trabalho. o globo. [Disponível em http://oglobo.globo.com/sociedade/tecnologia/mulheres-aindasao-poucas-no-mercado-de-computacao-12242530 - Acesso em 26 MAR.2018].

Moro, M. M., Weber, T., and Freitas, C. M. D. S. (2010). Women in brazilian cs research community: The state-of-the-art. In Cater-Steel, A. and Cater, E., editors, Women in Engineering, Science and Technology: Education and Career Challenges, chapter 14, pages 301-317. IGI Global.

Nakamura, F., Almeida, T., de Freitas, R., and Lauschner, T. (2017). Hora do vestibular: o que as estudantes do ensino médio almejam fazer? In WIT 2017, 11o Women in Information Technology, pages 1238-1242, São Paulo, Brasil.

Pessoa, M. S. P., Tamayo, S. C., and Raiol, J. R. (2017). Aumento da participação feminina em competições de programação tecnológicas através da criação de grupos de treinamento e pesquisa. In WIT 2017, 11 o Women in Information Technology, pages 1228-1232, São Paulo, Brasil. 